\title{
DESENCONTROS E DESENCANTOS DA FUNÇÃO SOCIAL DA TERRA: IMPASSES À SOBERANIA ALIMENTAR E Â REFORMA AGRÁRIA
}

\author{
Disencounters and disenchantments of the land social function: impasses to the food \\ sovereignty and the agrarian reform
}

Eliane Tomiasi Paulino*

*Professora Associada do departamento de geociências da Universidade Estadual de Londrina - eliane.tomiasi@gmail.com.

Recebido em 28/03/2019. Aceito para publicação em 15/04/2019.

Versão online publicada em 26/04/2019 (http://seer.ufrgs.br/paraonde)

\begin{abstract}
Resumo: Esse texto conjuga uma análise de dados sobre a agricultura brasileira dentro de uma perspectiva metodológica da Geografia Agrária, onde o objetivo é identificar suas repercussões do ponto de vista agrário. Para tanto, recorre-se à análise das relações de poder partindo das contradições de classe que definem tanto coalisões quanto inconciliabilidades, privilegiando como marco temporal o Governo do PT e referências empíricas do estado do Paraná. Conclui-se que a aposta na coalisão de classes, da qual resultaram ganhos pontuais ao campesinato, paralelamente ao fortalecimento do pacto latifundista, foi decisiva para a eliminação do princípio constitucional da função social da terra e, com ela, retrocessos que a sociedade brasileira apenas começa a experimentar, a começar pela renúncia à democracia.
\end{abstract}

Palavras-chave: Políticas agrárias; pactos de classe; concertação latifundista.

\begin{abstract}
The purpose of this text is to analyze data on Brazilian agriculture within a methodological perspective of Agrarian Geography, where the objective is to identify some repercussions to the agrarian question. In order to do so, we pay attention to the power relations starting from the contradictions of class that define coalitions and irreconcilables interests. The temporal frame is the time of de PT government and the empirical references are the Paraná's state. We conclude that bet in class coalitions with reconciliation of interests, resulted of the punctual improvements for the peasantry, but in strong deepening of the latifundist pact. All was decisive for the elimination of the constitutional principle of the land social function, the first step towards the loss of democracy in Brazil.
\end{abstract}

Key-words: Agrarian policies; class pacts; latifundist concertation.

\section{Introdução}

Esse trabalho se propõe a uma reflexão sobre os impasses do ordenamento fundiário segundo os critérios constitucionalmente estabelecidos, privilegiando como recorte temporal o período em que o Partido dos Trabalhadores governou o Brasil, com alguns acenos sobre fenômenos instaurados após o impeachment ocorrido em 2016.

Por ser este um tempo dos mais densos em termos de mudança de legislação ordinária e mesmo da Constituição, sem falar na sucessão de escândalos e denúncias acolhidas pelo ministério público que envolvem desde o Presidente da República até os donos e representantes das maiores empresas do país, não há ainda o assentamento mínimo dos acontecimentos e fatos para que a análise se estenda a este presente nebuloso e ao futuro tão temerário quanto o pode ser, em sendo mantidas as mudanças aqui apontadas, o que inclui desde a investida sobre as terras públicas até o recuo jurídico na regulamentação das relações de trabalho no campo.

Combinado a este hiato temporal, espacialmente busca-se articular as escalas nacional, regional e local, com particular ênfase no estado do Paraná. Justifica-se tal recorte por ser este o estado que ocupa a décima quinta posição dentre os 27 estados da federação, em termos de extensão territorial, 
mas que comparece como o segundo maior produtor agrícola nacional, tendo contribuído com mais de 41,5 milhões de toneladas de grãos no ano safra que se encerra com a colheita de inverno do corrente ano (CONAB, 2017). Escapar ao lugar comum das análises onde volumes e números dão o tom da construção ideológica sobre eficiência sem contradições é a proposta deste texto.

\section{o agrícola como expressão da fração menor do agrário em face dos passivos territoriais}

Em consonância com o padrão da agricultura hegemônica no país, no Paraná a soja e o milho igualmente predominam em termos de área lavrada e volume colhido, a ponto de o estado comparecer, reiteradamente, como o segundo produtor nacional destes dois grãos. (CONAB, 2017).

A despeito de ambas serem lavouras intensivas em capital, logo desfavoráveis ao amealhamento de renda proveniente da prevalência do fator trabalho na produção, ao que Ploeg (2008) denomina de artesanalidade, no Paraná o melhor fracionamento da terra se traduz no fato de $48 \%$ dos dividendos da produção agropecuária provir dos estabelecimentos cuja área média é de 12,3 hectares cada (IBGE/SIDRA, 2017).

Conforme demonstrado por Paulino (2015) isso somente é possível graças à diversificação produtiva própria dos pequenos estabelecimentos. A título de exemplo, o estado ocupa o primeiro posto na produção de orgânicos, mas também na produção convencional de feijão, centeio, cevada e trigo, sem falar na importância da pecuária leiteira, avicultura e suinocultura, atividades onde o fator trabalho é tão relevante que, em geral, pouco interesse desperta nos empresários do campo.

Outrossim, a superioridade campesina, em termos de geração de renda, põe a nu a importância da agricultura camponesa que, durante o período aqui analisado, vivera seu melhor momento, em face das políticas públicas orientadas para esse segmento, a exemplo de programas importantes como o Plano Nacional de Agroecologia e Produção Orgânica (PLANAPO), Programa de Aquisição de Alimentos (PAA), Programa Nacional de Alimentação Escolar (PNAE), Programa Nacional de Fortalecimento da Agricultura Familiar (PRONAF), Programa Minha Casa Minha Vida Rural (PMCMV), dentre outros.

Embora os recursos a eles destinado tenham estado longe da equanimidade, em comparação ao que o governo disponibilizara aos empresários rurais, o fato é que fizeram diferença no campo, a ponto de despertar profundas inquietações de classe, das quais floresceram as condições para o golpe parlamentar que levara Michel Temer ao poder em 12 de maio de 2016.

Seu primeiro ato, ainda na condição de interino, foi a extinção de ministérios fundamentais ao aparelhamento de um Estado menos curvado ao absoluto monopólio de classes, dentre eles o Ministério do Desenvolvimento Agrário (MDA), no seio do qual haviam frutificado os programas supra mencionados.

Assim foram se insinuando os sinais da forte descontinuidade que sobreviria ao período em análise, tendo sido decisivo para tanto a realização de alianças que invisibilizaram o latifúndio e forjaram uma imagem de pujança econômica associada à grande propriedade, sem respaldo nos fatos: de acordo com o último Censo Agropecuário (IBGE/SIDRA, 2017), a receita média dos estabelecimentos paranaenses com mais de 1.000 hectares foi de 741,19 reais por hectare, ao passo que os com menos de 10 hectares faturaram 3.632,46 reais em igual fração de terra, ou seja, cinco vezes mais.

Mais discrepante ainda são os resultados em escala nacional: para o Brasil, os valores foram de, respectivamente, $R \$ 309,12$ e $R$ \$2.793,20, logo nove vezes mais. Na escala local, a tendência não foi muito diversa da regional: em Londrina, a diferença em dividendos por hectare entre os estabelecimentos com mais de 1000 e menos de 10 hectares foi de quatro vezes e meia, mais precisamente de $\mathrm{R} \$ 756,30$ e $\mathrm{R} \$ 3.401,33$, respectivamente, conforme mostra a figura 1 , a seguir.

ParaOnde!?, Porto Alegre, v.11, n.1, p.29-35, 2019. http://seer.ufrgs.br/paraonde

Edição Especial: "Geografia e transformações socioespaciais: dinâmicas agrárias e políticas do desenvolvimento regional" 


\section{Figura 1 - Receita bruta anual segundo estratos de área $(R \$ / h a)$}

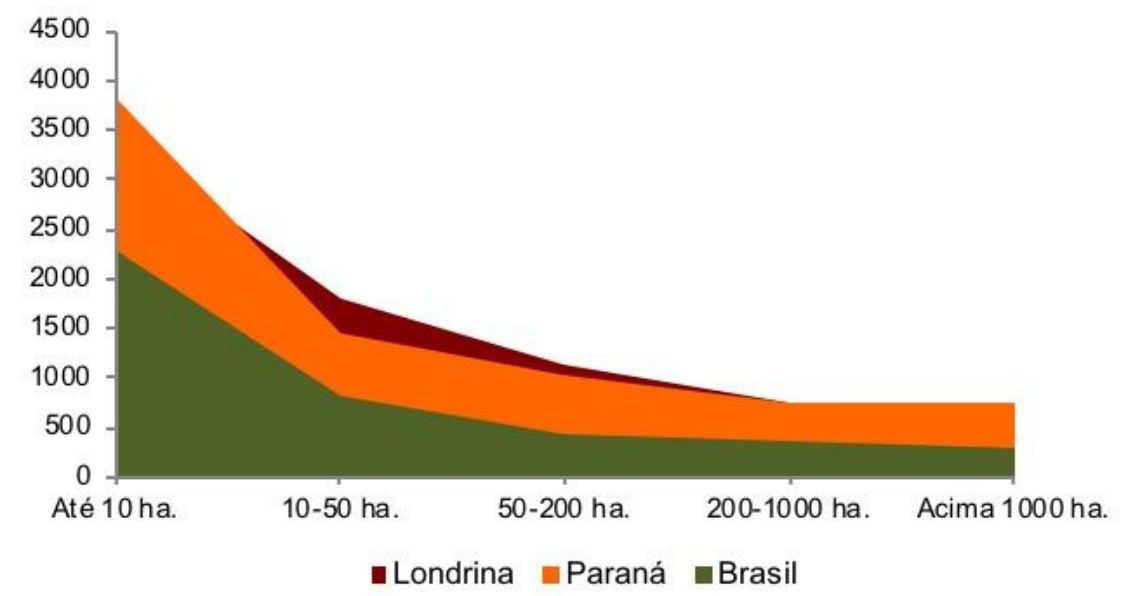

Fonte: IBGE/SIDRA, 2017.

Tais resultados, que confrontam as estratégias históricas de negligenciamento da agricultura familiar em favor da agricultura capitalista, merecem ser analisados à luz de ingredientes típicos do recorte temporal proposto, cabendo justificar a escolha pelo município de Londrina: trata-se de um município onde a tecnificação está amplamente difundida no campo. Ali está instalada a Embrapa soja, a unidade pública de pesquisa que desde os anos 1970 vem se dedicando à melhoria biotecnológica da cultivar mais importante do agronegócio brasileiro, aqui tomado como cadeia.

Observa-se que a diferença de receita por unidade de área é inversamente proporcional ao tamanho das propriedades, ou seja, quanto maior, mais ineficiente ela é. Nesses termos, a eficiência é um atributo da pequena propriedade, exatamente o oposto do que proclamam os defensores do latifúndio. Evidentemente essa resposta não se deve à recursos técnicos que pudessem torná-la competitiva frente às grandes.

0 fato é que a enorme diferença de receita entre os camponeses e os capitalistas do campo não poderá ser explicada no plano da produção, mas sim no da não produção: enquanto os camponeses têm que tornar sua terra produtiva para reproduzir-se enquanto tal, a maioria dos proprietários privados capitalistas da terra não o faz.

É a manutenção da propriedade ociosa, exceto em condições de auferimento da renda diferencial mais vantajosa do que o auferimento da renda absoluta, que o explica: a isso denominamos latifúndio improdutivo, o qual é tão pronunciado no Brasil a ponto de derrubar significativamente a renda média da propriedade produtiva capitalista, a que denominados de latifúndio produtivo. Como ensinam Fabrini (2008) e Fernandes (2006), enquanto o primeiro exclui pela não produção, ou seja, pela manutenção de terras sem cultivo digno de nota, o segundo exclui pela produção, baseada em monocultivos e manejos tecnicamente orientados para dividendos imediatos, logo em economia de mão de obra e desdém à parcimônia ambiental.

Ambos são assim conceituados por não atenderem a preceitos constitucionais que estabelecem como princípio ao reconhecimento do direito de propriedade o cumprimento da função social. Como ensina Marés (2003), somente o cumprimento da função social reveste a terra da proteção jurídica chancelada no direito de propriedade; segundo o jurista, aquela que a descumpre, propriedade não é, daí o argumento de que qualquer propriedade, mesmo intensamente explorada, porém fora dos marcos da função social, é igualmente um latifúndio. Como tal, é passível de desapropriação para fins de reforma agrária, contudo esse artigo da Constituição segue como letra morta.

Um parâmetro não negligenciável tem a ver com a extensão dos imóveis: a área média de 95\% dos

Para0nde!?, Porto Alegre, v.11, n.1, p.29-35, 2019. http://seer.ufrgs.br/paraonde

Edição Especial: “Geografia e transformações socioespaciais: dinâmicas agrárias e políticas do desenvolvimento regional” 
agricultores brasileiros é ligeiramente superior a 20 hectares, medida que não alcançaria um módulo fiscal para a maioria, sendo este o mínimo considerado pela legislação brasileira para a viabilidade econômica das famílias que trabalham e vivem no campo. No caso do Paraná, cerca de $93 \%$ dos estabelecimentos tem área média de 16 hectares. Ocorre que a média é a arte de ocultar os extremos; depurando-os chega-se ao dado de que 52,8\% dos agricultores brasileiros estão estabelecidos em unidades de produção com área média de menos de 2,9 hectares (IBGE/SIDRA, 2017).

Há nisso uma verdadeira interdição à viabilidade econômica do campesinato e isso é resultado da estrutura jurídica da propriedade. A figura 2, a seguir, revela os extremos da estrutura fundiária segundo a propriedade da terra.

Figura 2 - Monopólio fundiário no Brasil segundo extremos

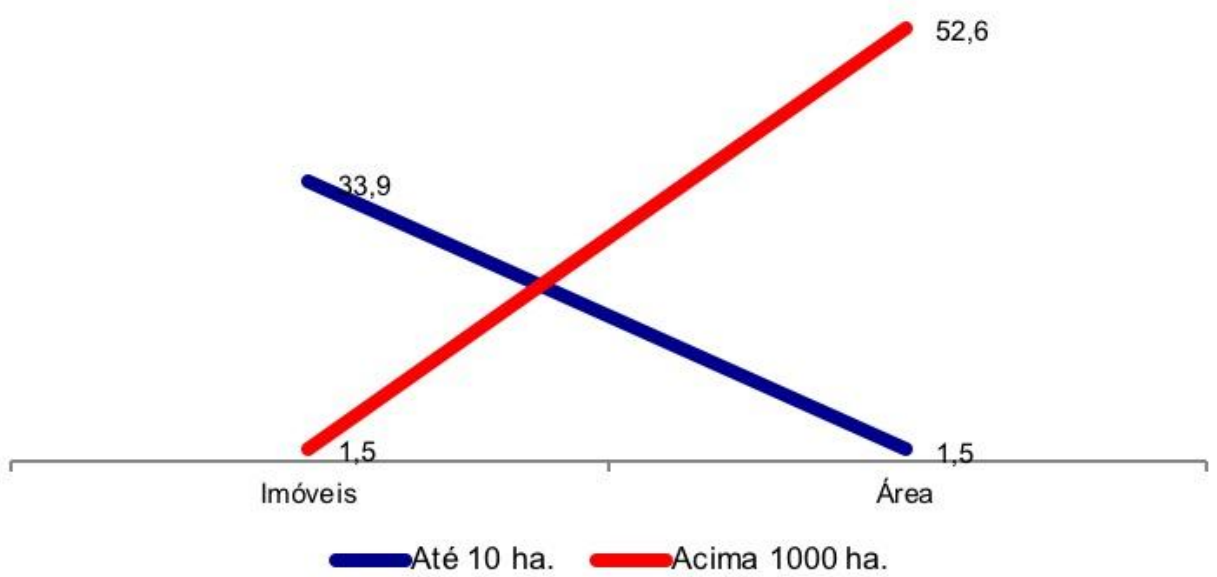

Fonte: INCRA, 2011.

Essa estrutura da propriedade revela por si a enorme capacidade que tem os latifundiários de dispor das instituições como coisa sua. As alianças feitas pelo governo do PT com essa classe são a melhor evidência disso, já que as reformas estruturais, dentre elas a reforma agrária, foi mais figura de retórica do que propriamente ação territorial, a que efetivamente teria feito diferença no jogo político da luta de classes. As migalhas que couberam aos camponeses e aos trabalhadores em geral não poderiam quebrar as estruturas hegemônicas de classe, reforçadas pelo dinheiro público que fluiu como nunca, traduzindo-se em tempos de bonança ímpar, como mostra a figura 3 , a seguir. 
Figura 3 - Relação entre crédito diponibilizado e geração de valor na agricultura brasileira

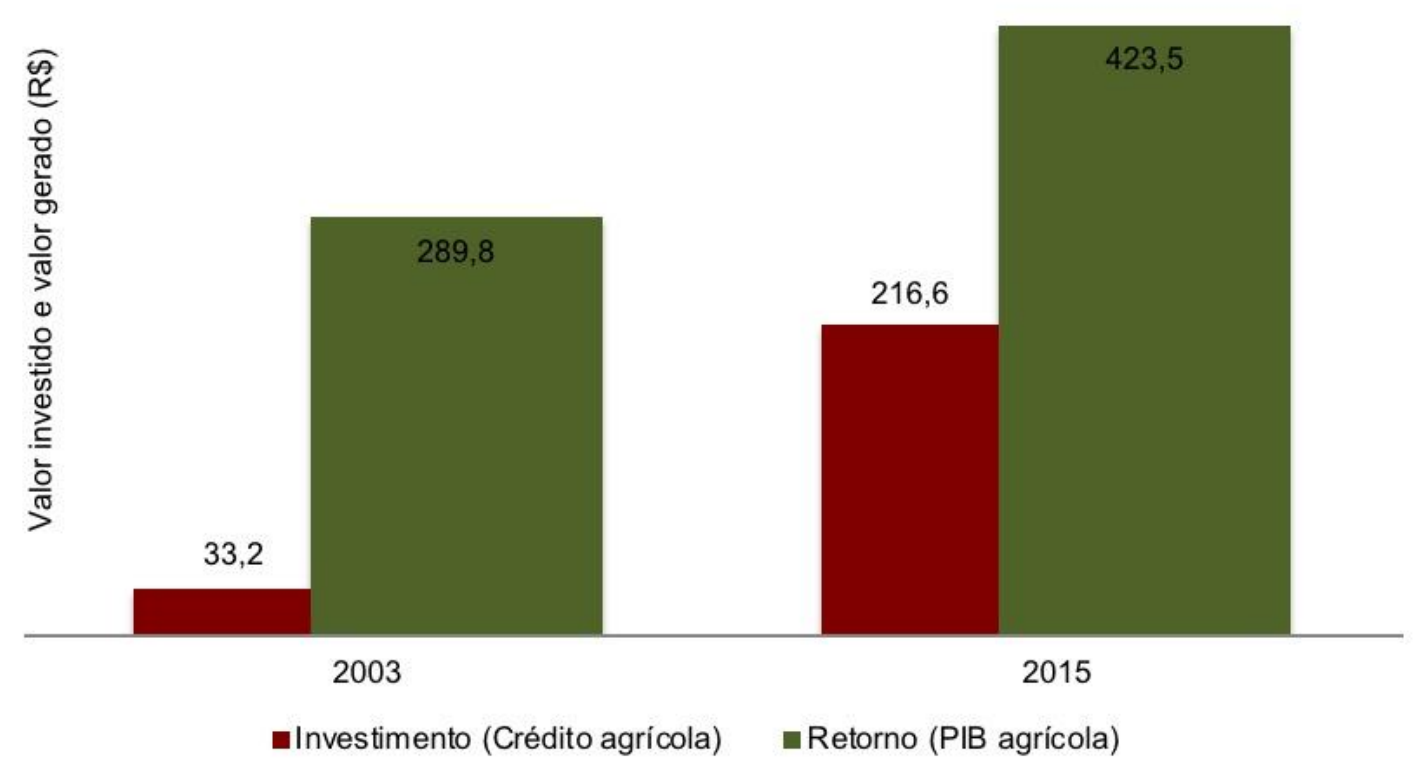

Fonte: IBGE/SIDRA, 2017.

A figura mostra uma situação paradoxal: seria de se esperar que ao aumento do crédito, corresponderia uma tendência de aumento proporcional do PIB, o que não aconteceu. Enquanto o crédito agrícola foi multiplicado em aproximadamente 6,5 vezes, o PIB mostrara uma curva ascendente tímida, sendo multiplicado por pouco menos que 1,5 vezes.

Pode-se concluir que, caso o dinheiro público tenha sido efetivamente investido na agricultura, tratou-se de investimento inócuo em grande medida. Importante destacar que entre 2003 e 2015 a participação da agricultura capitalista neste bolo jamais foi inferior a 82\% (Bianchini, 2016, p. 106). Ao cruzar tais indicativos com a dos valores brutos da produção expressos na figura 1, verifica-se que esta é que foi a responsável pelo malogro, em termos de retornos proporcionais, da política agrícola generosa.

Não que se advogue aqui a tese de que o Estado deveria se retirar do fomento à agricultura, ainda que neste período poucos foram os setores tão generosamente privilegiados pelo erário público. Ao contrário, defende-se a necessidade de equanimidade no acesso ao fundo público, o que significa advogar ampliação das políticas de fomento à agricultura camponesa, bem como a retomada da pauta da reforma agrária, severamente golpeada neste período. Se com tão pouca terra e tão modestos recursos o campesinato conseguiu tais proezas econômicas, o que não poderia fazer pelo Brasil caso fossem atenuados os obstáculos da gula ruralista, que toma para si a terra e o crédito, sem qualquer compromisso com a função social que lhe corresponde.

\section{Considerações Finais}

Um dos desafios dos estudos que se propõem a desvendar o agrário brasileiro é desmontar o insidioso discurso ideológico cujo fim é propugnar uma suposta revolução agrária pela via dos ativos agrícolas que emanam de uma agricultura tão profusa em ativos quanto em passivos territoriais, traduzidos nas assimetrias que constrangem a soberania alimentar, ao constranger os camponeses a

ParaOnde!?, Porto Alegre, v.11, n.1, p.29-35, 2019. http://seer.ufrgs.br/paraonde

Edição Especial: "Geografia e transformações socioespaciais: dinâmicas agrárias e políticas do desenvolvimento regional" 
fazerem o impossível, caso o parâmetro seja o latifúndio blindado pela nomenclatura mais usual: o agronegócio.

Buscou-se aqui, por meio do simples exercício com proporcionalidades em termos de terras e recursos, expressar em que consiste, na prática, a função social da terra, embora aqui tenhamos nos dedicado apenas à variável econômica, a produtividade, esta que é somente uma dentre as quatro que a instituem, conforme determina a Constituição em vigor.

É o critério da função social que reveste de atualidade o conceito de latifúndio, e esse se aplica tanto às terras improdutivas quanto às intensivamente exploradas, pois além da eficiência econômica, tipificada pela Lei 8.629/1993, toda propriedade deveria estar quites com a legislação ambiental, com a legislação trabalhista e com o bem estar dos que vivem e trabalham na terra. 0 célere desmonte da legislação que as resguarda é a evidência mais cabal do seu amplo descumprimento.

Mais uma vez, as pautas includentes profundamente entranhadas na questão da terra persistem como utopia, a mover as lutas dos camponeses e dos trabalhadores que não sucumbiram nem ao assédio desmobilizador nem ao ódio de classe, travestido de ódio ao PT.

Ao menos, evidente está que a inclusão pelo mercado, com enriquecimento dos que já são ricos e com a ascensão da classe média, graças ao investimento público em amplos setores da economia, não se traduz em ganhos civilizatórios, muito pelo contrário. Colhemos deste período a flexibilização do Estado de Direito ao gosto da ascensão fascista que, apesar de visceral a esta sociedade que jamais conseguira destruir a obra da escravidão, foi constrangida durante o sopro de uma democracia de retardatária e difícil frutificação.

Como ensina Marx (1974) a enorme vitalidade da classe proprietária emana da sua capacidade de dispor da força que a renda fundiária pode proporcionar. Isso não afeta apenas os camponeses, mas a sociedade em geral, pois sempre que as terras puderem ser privatizadas e dilapidadas, segundo o crivo da receita imediata, das negociatas e das armas, a violência dará o tom do movimento da história, como temos visto nos massacres que cobram o tributo da irresoluta justiça agrária no Brasil.

\section{Referências}

BIANCHINI, Valter. Vinte anos do PRONAF 1995 - 2015: avanços e desafios. Brasília: MDA, 2015. Disponível em:

<http://www.mda.gov.br/sitemda/sites/sitemda/files/ceazinepdf/PRONAF_20_ANOS_VALTER_BIA NCHINI.pdf $>$. Acesso em: 04 maio 2017.

BRASIL. Constituição da República Federativa do Brasil. São Paulo: Saraiva, 1988.

BRASIL. Lei 8.629, de 25 de fevereiro de 1993. Dispõe sobre a regulamentação dos dispositivos constitucionais relativos à reforma agrária, previstos no Capítulo III, Título VII, da Constituição Federal. Brasília, Diário Oficial da União, 26 fev. 1993.

CONAB. Companhia Nacional de Abastecimento. Acompanhamento da safra brasileira de grãos: oitavo levantamento, safra 2016/17. Brasília, v. 4, p. 1-144 maio 2017.

FABRINI, João Edmilson. Latifúndio e Agronegócio: semelhanças e diferenças no processo de acumulação de capital. Revista Pegada, Presidente Pudente, v. 9, n. 1, p. 35-62, 2008.

FERNANDES, Bernardo Mançano. Um nome para modernizar o sistema de latifúndio. Jornal da Unesp, Presidente Prudente, v. 20, n. 211, 2006.

IBGE/SIDRA. Sistema IBGE de Recuperação Automática. Banco de Dados Agregados. Disponível em: <http://sidra.ibge.gov.br>. Acesso em: 2017.

ParaOnde!?, Porto Alegre, v.11, n.1, p.29-35, 2019. http://seer.ufrgs.br/paraonde

Edição Especial: "Geografia e transformações socioespaciais: dinâmicas agrárias e políticas do desenvolvimento regional" 
INCRA. Sistema Nacional de Cadastro Rural: estatísticas cadastrais situação jurídica. Banco de dados: 2011

MARÉS, Carlos Frederico. A função social da terra. Porto Alegre: Safe, 2003.

MARX, Karl. 0 capital. Livro 3, Volume 6. Rio de Janeiro: Civilização Brasileira, 1974.

PAULINO, Eliane Tomiasi. Abordagens teórico-metodológicas em Geografia Agrária: problematizações necessárias. In: ROSAS, Celbo A.R.F. Perspectivas da Geografia Agrária no Paraná: abordagens e enfoques metodológicos. Ponta Grossa: Estúdio Texto, 2015. p. 61-84.

PLOEG, Jan Douwe van der. Camponeses e impérios alimentares: lutas por autonomia e sustentabilidade na era da globalização. Porto Alegre: UFRGS, 2008. 